\title{
Crystallization of II-VI Semiconductor Compounds Forming Long Microcrystalline Linear Assemblies
}

\author{
Marcelino Becerrila*, Óscar Portillo-Moreno ${ }^{\mathrm{b}}$, Rosendo Lozada-Moráles ${ }^{\mathrm{c}}$, \\ Rafael Ramírez-Bon ${ }^{\mathrm{d}}$,Ramón Ochoa-Landín ${ }^{\mathrm{e}}$,Feliciano Sánchez-Sinencio ${ }^{\mathrm{a}}$, \\ Jaime Santoyo-Salazar ${ }^{\mathrm{a}}$,Orlando Zelaya-Angel ${ }^{\mathrm{a}}$ \\ ${ }^{a}$ Departamento de Física, Centro de Investigación y de Estudios Avanzados del IPN, \\ Apdo. Postal 14740, México, D.F., 07360, México \\ ${ }^{\mathrm{b}}$ Facultad de Ciencias Químicas, Benémerita Universidad Autónoma de Puebla, \\ 14 Av. Sur y Av. San Claudio, Col. San Manuel, 72570 Puebla, México \\ 'Facultad de Ciencias Físico-Matemáticas, Benémerita Universidad Autónoma de Puebla, \\ 14 Av. Sur y Av. San Claudio, Col. San Manuel, 72570 Puebla, México \\ ${ }^{\mathrm{d} C e n t r o ~ d e ~ I n v e s t i g a c i o ́ n ~ y ~ d e ~ E s t u d i o s ~ A v a n z a d o s ~ d e l ~ I P N, ~ U n i d a d ~ Q u e r e ́ t a r o, ~}$ \\ Apdo. Postal 1798, Querétaro, Qro. 76001. México \\ 'Departamento de Física, Universidad de Sonora, Apdo. Postal 142, Hermosillo, Son. 83190, México
}

Received: June 15, 2012; Revised: October 15, 2012

In this work we report the formation of long microcrystalline linear self-assemblies observed during the thin film growth of several II-VI compounds. Polycrystalline $\mathrm{CdTe}, \mathrm{CdS}, \mathrm{CdCO}_{3}$, and nanocrystalline CdTe:Al thin films were prepared on glass substrates by different deposition techniques. In order to observe these crystalline formations in the polycrystalline materials, the thin film growth was suspended before the grains reached to form a continuous layer. The chains of semiconductor crystals were observed among many isolated and randomly distributed grains. Since CdTe, CdTe:Al, $\mathrm{CdS}$ and $\mathrm{CdCO}_{3}$ are not ferroelectric and/or ferromagnetic materials, the relevant problem would be to explain what is the mechanism through which the grains are held together to form linear chains. It is well known that some nanocrystalline materials form rods and wires by means of electrostatic forces. This occurs in polar semiconductors, where it is assumed that the attraction forces between surface polar faces of the small crystals are the responsible for the chains formation. Since there are not too many mechanisms responsible for the attraction we assume that a dipolar interaction is the force that originates the formation of chain-like grain clusters. The study of this property can be useful for the understanding of nucleation processes in the growth of semiconductor thin films.

Keywords: II-VI compounds, semiconductors, growth processes, grain-chains, PACS 61.72.uj; 6182.Fk; 81.10.jt.; 81.10.-h

\section{Introduction}

Cadmium telluride (CdTe) and cadmium sulfide (CdS) are II-VI semiconductor compounds with direct energy band gap of 1.5 and $2.4 \mathrm{eV}$, respectively. Due to their interesting properties, polycrystalline films of both compounds are currently employed in several kinds of thin film electronic devices ${ }^{1-4}$. The feasibility to obtain these semiconductors in the form of nanoparticles with variable size and tunable energy band gap, showing strong quantum confinement effects is also an important reason for the study of these compounds and a number of reports on this topic can be found in literature ${ }^{5-10}$. Other types of nanostructures such as nanowires, nanobelts, nanorods, etc. based on these materials, mainly CdS, have also been reported ${ }^{11-14}$. Furthermore, these nanostructures with novel physical and

*e-mail: becerril@ fis.cinvestav.mx chemical properties have found applications in devices such as solar cells and thin film transistors (TFTs) at the nanoscale level ${ }^{11,14}$. Therefore, the understanding of the growth mechanisms of nanostructures and self-assembled structures of CdS and CdTe is of major relevance to extend the potential applications of these semiconductors to the nanoscale level.

Close spaced sublimation (CSS) and chemical bath deposition (CBD) and thermal evaporation (TE) are the most used deposition techniques to grow polycrystalline thin films of CdTe and CdS, respectively. The knowledge of all the mechanisms involved in the growth process of micro or nanocrystalline thin films is necessary to address the shape, compactness and size of the semiconductor grains. The conventional semiconductor deposition processes, such as CSS, CBD and TE, produces typically polycrystalline 
films with micro or nano grain sizes and rarely is observed the formation of assembled micro or nanostructures. This is because the special conditions to obtain these assembled structures are not fulfilled during the thin film growth process, except in seldom cases. In this work we report the formation of mycro and nanocrystal linear chains of CdS and CdTe obtained on glass substrates by conventional CSS, CBD and rf sputtering techniques. We discuss the formation of the linear chains as an early or intermediate stage during the film deposition on glass substrates of the polycrystalline thin films ${ }^{15-18}$. Among the interaction forces which can cause particles aggregation are electrical and magnetic dipolar (or multipolar) attraction ${ }^{19,20}$, Van der Waals $^{20}$, depletion attraction ${ }^{21}$, optical force ${ }^{22}$, etc. Most of these interactions are of electrical nature. Actually, linear assemblies are widely studied at nanodimensional levels, because as compared with microcrystalline dimensions attraction forces are negligible because their short-range interaction. However, given the polar character of II-VI semiconductor compounds, we think that there is a high probability that attraction forces, causing the observed particle aggregation, have dipolar origin. This fact can be useful for the understanding of interaction forces between grains in polycrystalline and nucleation processes in $\mathrm{CdTe}$ and CdS thin films and in other similar semiconductors.

\section{Experimental}

In all the cases the semiconductor thin films were deposited on glass substrates. Polycrystalline CdTe was grown by means of the CSS conventional technique at source temperature of $650{ }^{\circ} \mathrm{C}$ and substrate temperature of $550{ }^{\circ} \mathrm{C}$. To obtain the CdTe:Al thin films, Al was first deposited by conventional thermal evaporation onto glass substrate, later CdTe was sputtered onto the Al/glass, the $\mathrm{Al}$ was thermal diffused into the CdTe by annealing in $\mathrm{Ar}$ at $350{ }^{\circ} \mathrm{C}$ for half hour. $99.999 \%$ purity CdTe powder from Cerac was utilized in the source. The $\mathrm{CdS}$ thin films were grown by the $\mathrm{CBD}$ technique at $70{ }^{\circ} \mathrm{C}$, employing an ammonia-free process including $\mathrm{CdCl}_{2}(0.05 \mathrm{M}), \mathrm{Na}_{3} \mathrm{C}_{6} \mathrm{H}_{5} \mathrm{O}_{7}(0.5 \mathrm{M}), \mathrm{KOH}$ $(0.5 \mathrm{M})$ and $\mathrm{CS}\left(\mathrm{NH}_{2}\right)_{2}(0.5 \mathrm{M})$, as the precursor reagents ${ }^{23-25}$. $\mathrm{CdCO}_{3}$ thin film deposition was also done by the CBD technique, $\mathrm{CdCO}_{3}$ is produced by employing the same bath employed to get $\mathrm{CdS}$ films, but at room temperature (RT). High purity salts reagents (concentrations) used in the preparation, in this last case, were: $\mathrm{CdCl}_{2}(0.02 \mathrm{M})$, $\mathrm{KOH}(0.15 \mathrm{M}), \mathrm{NH}_{4} \mathrm{NO}_{3}(1.5 \mathrm{M})$, and $\mathrm{SC}\left(\mathrm{NH}_{2}\right)_{2}(0.2 \mathrm{M})$. More details of the growth processes have been previously reported elsewhere ${ }^{15-18}$. X-ray diffraction (XRD) patterns of samples were registered using the $\mathrm{CuK} \alpha$ line of a D5000 Siemens diffractometer. Images of long chains of CdTe and $\mathrm{CdCO}_{3}$ were obtained using a Leica DM LS2 microscope. The surface morphology of the CdS thin films was analyzed by atomic force microscopy (AFM) images by using an Instrument Veeco Dimension 3100 System, Nanoscope IV in the tapping mode. Transmission electron microscopy (TEM) apparatus employed was a Jeol 2010 working at $200 \mathrm{keV}$, the CdTe:Al layers were detached from the substrate and attached onto the TEM-grills.

\section{Results and Discussion}

Figure 1a, b show the XRD patterns of CdTe deposited by CSS and CdTe:Al, respectively with diffraction peaks at about $23.7,39.2$ and $46.5^{\circ}$, corresponding to the diffraction signals due to the (111), (220) and (311) crystalline planes of the cubic zincblende (ZB) phase of CdTe. In both cases, the CdTe films have a preferred crystalline orientation along the (111) direction with much more intense and narrow (111) diffraction peak for the CSS-CdTe films due to their better crystalline characteristics. The introduction of aluminum atoms in the crystalline lattice of sputtered CdTe:Al films produces broader and less intense diffraction peaks in the XRD pattern. From these XRD patterns the constant lattice of CdTe was determined in each case and the resulting values were $6.465 \AA$ and $6.518 \AA$ for the CSS and sputtered films, respectively. Comparing with lattice constant value of bulk CdTe, $6.477 \AA^{26}$, these lattice constant values for the polycrystalline CdTe films indicates that the crystalline lattice is under compressive stress in the case of CSS films and under tensile stress in the sputtered films. On the other hand, Figure 1c shows the XRD pattern of the CdS film deposited for 10 minutes, where it is observed an intense diffraction peak at about $26.6^{\circ}$, related with the (002) crystalline planes of the hexagonal wurtzite CdS phase. The weak diffraction signals aside the (002) peak, at about 24.8 and $28.2^{\circ}$ are related with the (100) and (101)

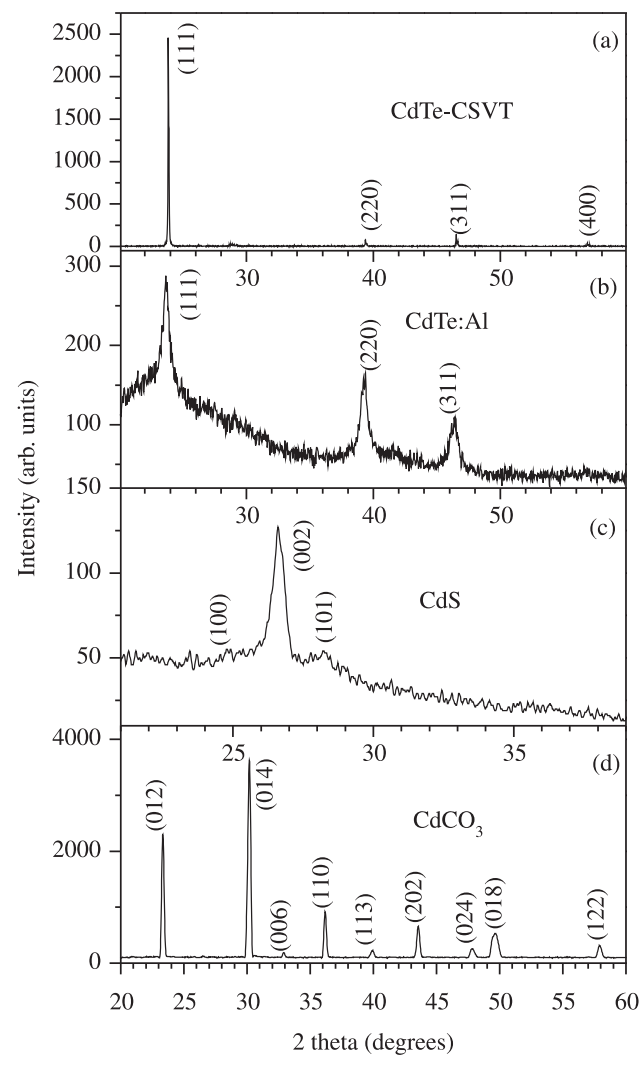

Figure 1. X-ray diffraction patterns of a) CdTe polycrystalline film deposited by CSS, b) CdTe:Al polycrystalline film, c) CdS films deposited by CBD for 10 minutes and d) $\mathrm{CdCO}_{3}$ film. 
crystalline planes of this CdS phase. The CdS crystallites have the (002) preferred crystalline orientation as evidenced by the higher intensity of the (002) diffraction peak in this pattern. The $c$ lattice constant determined from the XRD data is $6.702 \AA$, which compared to that of CdS bulk, $6.713 \AA^{26}$, evidences that the film is under tensile stress. In Figure $1 \mathrm{~d}$ it is shown the XRD pattern of the chemically deposited $\mathrm{CdCO}_{3}$ film displaying several diffraction peaks related with the rombohedral crystalline phase. The labels in peaks of the pattern correspond to the crystalline planes of this $\mathrm{CdCO}_{3}$ phase. The most common structure (stable phase) of CdTe is zincblende, for CdS the stable phase is hexagonal and for $\mathrm{CdCO}_{3}$ the stable phase is rhombohedral. The latter phase can be obtained from a CBD process to prepare CdS with some particular growth-conditions as reported in Portillo-Moreno et al. ${ }^{16}$.

In Figure 2 the SEM image shows the surface morphology of the CSS grown CdTe polycrystalline film. The arrow indicates a long chain of microcrystals observed among the random distributed grains which form the uncompleted semiconductor film. The crystallite chain has a length of about $180 \mu \mathrm{m}$ and a width of about $10 \mu \mathrm{m}$. As stated above, these chains are rarely observed during the growth process of semiconductor films; actually it is an aleatory phenomenon and most of times they do not appear. On the other hand, a similar linear growth feature is observed in the TEM image of Figure 3, where a CdTe crystalline nanowire is exhibited, which looks at a glance, similar to the CdTe chain in image of Figure 2. The nanowire has a length of about $10 \mu \mathrm{m}$ and a width of about $50 \mathrm{~nm}$. Like in the case of CSS-CdTe surface image, the deposited material in this case is in general is formed of random spread nanoparticles with isolated and randomly distributed nanowires. Regarding CdS films, in Figure 4 it is shown 2-D AFM images of a) height profile and $b$ ) phase profile, measured in an area of $20 \times 20 \mu^{2}$, of a sample deposited for 2.5 minutes. Figure $4 \mathrm{c}, \mathrm{d}$ show the corresponding images measured in an area of $1 \times 1 \mu \mathrm{m}^{2}$. For each image, the $\mathrm{z}$-scale is indicated

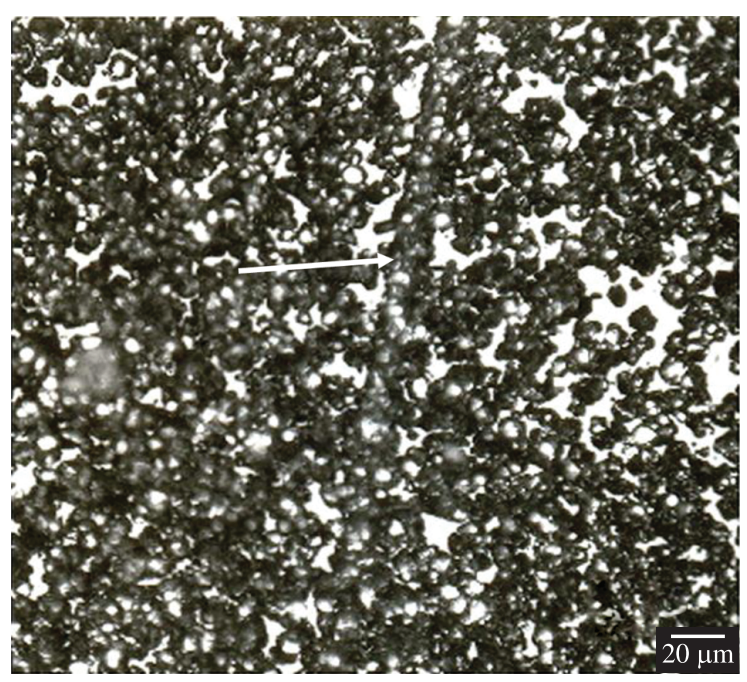

Figure 2. SEM surface image of a CdTe polycrystalline film deposited by CSS at $\mathrm{T}_{\mathrm{s}}=650^{\circ} \mathrm{C}$ and $\mathrm{T}_{\mathrm{g}}=550^{\circ} \mathrm{C}$. at the bottom. The images in Figure $4 \mathrm{a}$, b display a large number of particles agglomerated in well defined patterns following straight lines on a flat background. Some isolated particles can be also seen on the background. The straight lines which follow the agglomeration pattern of particles are approximately parallels. The images in Figure $4 c, d$ the granular structure of the linear arrays, where are observed the nanocrystalline formations. In this case the linear crystallite formations were observed at the early stages of the film formation. According to our report in Mazón-Montijo et al..$^{25}$ these particles correspond to the growth stage when the first nuclei of $\mathrm{Cd}(\mathrm{OH})_{2}$ are being transformed to $\mathrm{CdS}$ by cation exchange. Therefore, the particles are a mixture of $\mathrm{Cd}(\mathrm{OH})_{2}$ and $\mathrm{CdS}$ which with deposition time evolve to a $\mathrm{CdS}$ layer as shown by the XRD pattern in Figure 1c. The identification of the chemical species at the substrate was done by XPS measurements because the XRD pattern of this sample did not show any diffraction signal. Finally, we have also observed the linear crystallite formation during the chemical growth of $\mathrm{CdCO}_{3}-\mathrm{CdS}$ mixed films. In Figure 5 there is shown the unidimensional arrangement of grains of $\mathrm{CdCO}_{3}$ with a length of about $250 \mu \mathrm{m}$ and a width of about $10 \mu \mathrm{m}$, among a number of isolated and randomly distributed grains on a flat background. Therefore, the results observed in images of Figures 2-5 show that linear assemblies of grains at the nanometric and micrometric scale can be formed during the conventional deposition process of semiconductor polycrystalline thin films.

In non-ferroelectric or non-ferromagnetic materials no attraction forces are expected among crystals in polycrystalline materials of micro or nano dimensions. In general, when crystalline grains or clusters of grains are in contact among them or with a substrate Van der Waals forces are generated between contact surfaces, depending on the magnitude of the force, the grains can hold joined or can be easily removed. These types of attraction forces are normally weak. Besides, the most common interactions among nanocrystals ${ }^{19,27-30}$ and microcrystals ${ }^{31-33}$ in polycrystalline materials are forces of electric dipolar nature. In polar lattices, electric dipoles can exist in zincblende (ZB) and wurtzite (W) crystalline phases ${ }^{19,28-29}$. Formation of grain

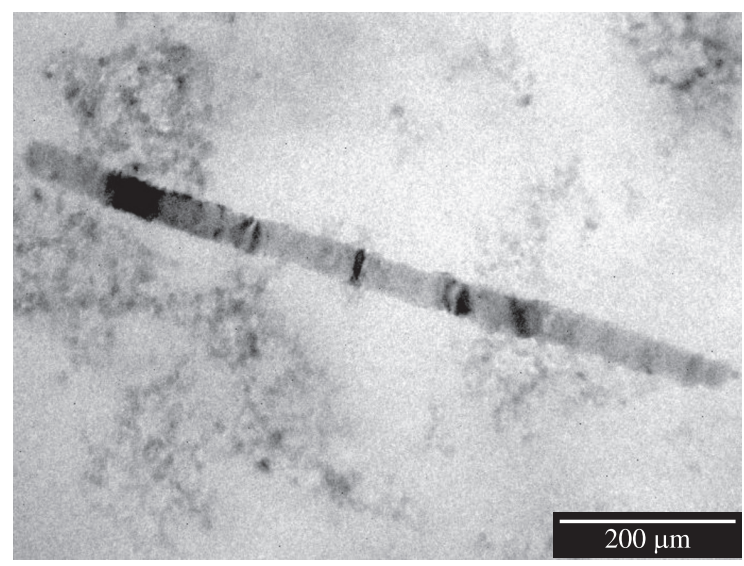

Figure 3. TEM image of a nanowire of CdTe formed during r.f. sputtering deposition process. 



Figure 4. Two-dimensional AFM images of the CdS sample deposited for 2.5 minutes: a) height profile in an area of $20 \times 20 \mu \mathrm{m}^{2}$, b) phase profile in an area of $20 \times 20 \mu \mathrm{m}^{2}$, c) height profile in an area of $1 \times 1 \mu \mathrm{m}^{2}$ and d) phase profile in an area of $1 \times 1 \mu \mathrm{m}^{2}$.

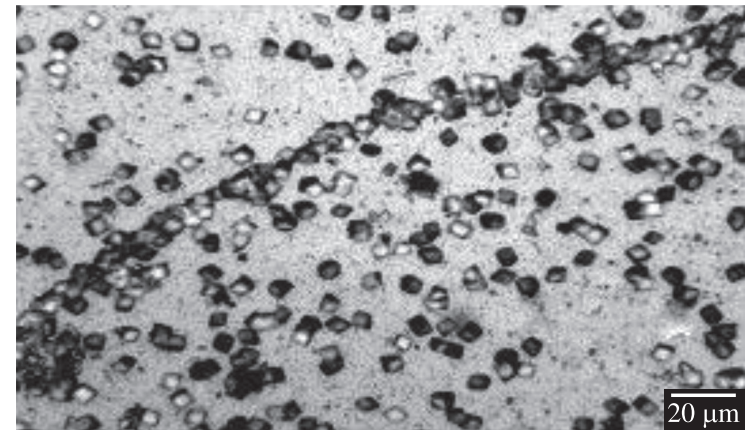

Figure 5. SEM image of the $\mathrm{CdCO}_{3}$ film grown by $\mathrm{CBD}$ at $50{ }^{\circ} \mathrm{C}$ and $\mathrm{pH}=8.3$. chains of ZB-CdTe nanoparticles has been explained by considering the existence of electric dipoles in determined crystalline directions of the nanocrystals ${ }^{19}$. ZB crystallizes predominantly as tetrahedrons, which because their high symmetry no polar axis in the crystalline lattice exists. However, if truncated tetrahedrons, through an (111) plane, are considered, a dipolar moment appears along this direction in the nanocrystals ${ }^{19}$. Like the terraces of truncated tetrahedrons, similar terraces have also been observed in wurtzite $\mathrm{ZnO}$ polycrystalline films, which give origin to polar surfaces ${ }^{34-35}$. Surface dipoles have also been reported in ZB-CdTe and W-CdS crystals ${ }^{27}$. We believe that this type of attraction forces are so weak because the charge on surfaces are not large enough to produce the needed electric field to 


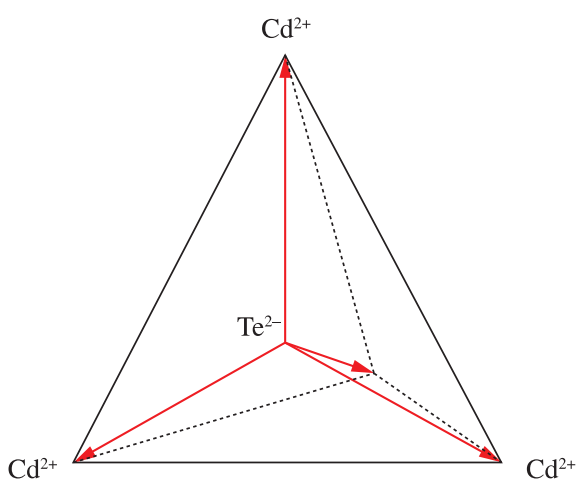

Figure 6. Four self-equilibrated dipoles in the ZB-CdTe lattice.

influence the position of microcrystals for the alignment, they probably are adequate to move nanocrystals as CdTe-Al chain of Figure 3. Larger fields can be produced by materials like ferroelectric solids. Zincblende and wurtzite lattices can be considered as constituted by regular tetrahedrons like that of ZB-CdTe displayed in Figure 6. The four dipoles observed in this scheme have a resultant value which is equal to zero. However, if the symmetry of the crystals is broken ${ }^{29}$, for instance, because a distortion produced by uniform and unidirectional strain due to sticking with the substrate ${ }^{36}$, or by an excess of density of vacancies ${ }^{37}$, a spontaneous polarization will be originated, similar to that of ferroelectric materials ${ }^{27,28,33}$. In CdTe and CdS the distortion is mainly originated by differences between thermal expansion coefficients of semiconductor and glass when they are grown at temperatures higher than room temperature. This seems to be the case for $\mathrm{CdTe}, \mathrm{CdS}$, and $\mathrm{CdCO}_{3}$ microcrystals of Figures 2, 4 and 5. Chains of these compounds were tried to grow by CSS and CBD on scratches made previously on substrates, but it was not possible. In some way, an effective electric polarization is the cause of long-chains of grains in nano-or-micro particulate films. No other different attraction than that type of polarization for the formation of chains-like clusters for these semiconductors could be argued, based in our experiments. It must be taken into account that two different growth techniques were employed to prepare these materials.

The contact between two polarized particles can mainly occur in two ways, as indicated in Figure 7a: Anti-parallel dipoles arrangement, and Figure 7b: Head-to-tail alignment. It can be concluded that in case (a) consecutive arrangement of grains leads to chains which can have arbitrary paths ${ }^{19}$, because the only restriction here is that particles must have anti-parallel dipoles, and lateral position between them is

\section{References}

1. Ferekides CS, Balasubramanian U, Mamazza R, Viswanathan V, Zhao H and Morel DL. CdTe thin film solar cells: device and technology issues. Solar Energy. 2004; 77:823-830. http:// dx.doi.org/10.1016/j.solener.2004.05.023

2. Romeo N, Bosio A, Canevari V and Podestá A. Recent progress on $\mathrm{CdTe} / \mathrm{CdS}$ thin film solar cells. Solar Energy. 2004; 77:795-801. http://dx.doi.org/10.1016/j. solener.2004.07.011

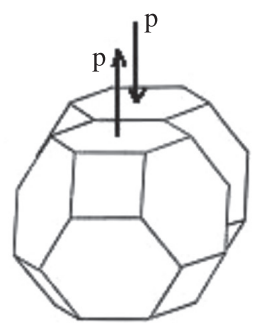

(a)

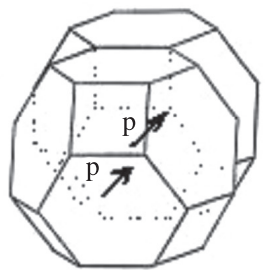

(b)
Figure 7. Crystals in contact due to attraction forces between them: a) antiparallel, b) head-to-tail. Dipoles in both figures are oriented along the (111) direction.

not important. On the other hand, in case (b) head-to-tail arrangement determines a defined direction for the packing of microcrystals. Furthermore, the energy is minimized in the second arrangement. The crystal-to-crystal formation shown by $\mathrm{CdTe}$ and $\mathrm{CdCO}_{3}$ microcrystals in Figures 2 and 5 suggests that the interaction between adjacent particles is head-to-tail. Anti-parallel arrangement tends to diminish excessively the resultant electric field. The randomly character of the formation of grain-chains in the growths seems to be related with an initial minimum number of lined-up crystals. Since dipolar electric field can increases slightly in the extent of more particles be aggregated to the chain, a critical number of aligned crystals must exist in order a long chain can be generated and a large probability exist that the same dipolar force occurs in $\mathrm{CdCO}_{3}{ }^{38}$. Consequently, it is assumed that dipolar attraction forces can exist among microparticles in such a way they put themselves in contact.

\section{Conclusions}

We reported the observation of linear crystalline assemblies of several compound semiconductors formed during conventional deposition processes. The formation of long chains of zincblende microcrystals of $\mathrm{CdTe}$, wurtzite $\mathrm{CdS}$, rhombohedral $\mathrm{CdCO}_{3}$ has been proposed based in the existence of polarization provoked by distortions of the lattice due to strains semiconductor/substrates originated by the growth processes. The alignment occurs under a head-to-tail arrangement.

\section{Acknowledgements} México.

This work was partially supported by CONACyT-

3. Ochoa-Landín R, Sastre-Hernández J, Vigil-Galan O and Ramírez-Bon R. Chemically deposited CdS by an ammonia-free process for solar cells window layers. Solar Energy. 2010; 84:208-214. http://dx.doi.org/10.1016/j. solener.2009.11.001

4. Arreola-Jardón G, González LA, García-Cerda LA, Gnade B, Quevedo-López MA and Ramírez-Bon R. Ammonia-free chemically deposited CdS films as active layers in thin film transistors. Thin Solid Films. 2010; 519:517-520. http://dx.doi. org/10.1016/j.tsf.2010.08.097 
5. Ramírez-Bon R, Espinoza-Beltrán FJ, Arizpe-Chávez $\mathrm{H}$, Zelaya-Angel $\mathrm{O}$ and Sánchez Sinencio F. CdTe nanostructures prepared by thermal annealing. Journal of Applied Physics. 1995; 77(10):5461-5463. http://dx.doi. org/10.1063/1.359244

6. Sotelo-Lerma M, Quevedo-López MA, Orozco-Terán RA, Ramírez-Bon R and Espinoza- Beltrán FJ. Characterization of CdS-NaX composite material synthesized in alkaline solution. Journal Physics Chemistry of Solids. 1998; 59:145-149. http:// dx.doi.org/10.1016/S0022-3697(97)00160-1

7. Arizpe-Chávez H, Ramírez-Bon R, Espinoza-Beltrán FJ, Zelaya-Angel O, Marín JL and Riera R. Quantum confinement effects in CdTe nanostructured films prepared by the RF sputtering technique. Journal Physics Chemistry of Solids. 2000; 61:511-518. http://dx.doi.org/10.1016/ S0022-3697(99)00258-9

8. Rodríguez-Fragoso P, González de la Cruz G, Tomás SA and Zelaya-Angel O. Optical characterization of CdS semiconductor nanoparticles capped with starch. Applied Surface Science. 2010; 257:581-584. http://dx.doi. org/10.1016/j.apsusc.2010.07.036

9. Peng X, Manna L, Yang W, Wickham J, Scher E, Kadavanich A et al. Shape control of CdSe nanocrystals. Nature. 2000; 404:59-61. PMid:10716439. http://dx.doi. org/10.1038/35003535

10. Jia Z, Tang Y, Jiang Y, Chen Z. The Controlled Synthesis of Single-Crystalline $\mathrm{CdCO}_{3}$ Nanoparticles with Different Morphologies. Journal of Nanoscience and Nanotechnology. 2009; 9:1593-1596. PMid:19441578. http:// dx.doi.org/10.1166/jnn.2009.C210

11. Wu PC, Ma RM, Liu C, Sun T, Ye Y and Dai L. High-performance CdS nanobelt field-effect transistors with high- $\mathrm{HfO}_{2}$ top-gate dielectrics. Journal of Material Chemistry. 2009; 19: 2125-2130. http://dx.doi.org/10.1039/ b822518d

12. Zhang $\mathrm{K}$ and Liu X. One step synthesis and characterization of CdS nanorod/graphene nanosheet composite. Applied Surface Science. 2011; 257:10379-10383. http://dx.doi.org/10.1016/j. apsusc.2011.06.087

13. Mondal SP, Dhar A and Ray SK. Optical properties of CdS nanowires prepared by dc electrochemical deposition in porous alumina template. Materials Science in Semiconductor Processing. 2007; 10:185-193. http://dx.doi.org/10.1016/j. mssp.2007.11.003

14. Chen F, Qiu W, Chen X, Yang L, Jiang X, Wang M et al. Large-scale fabrication of CdS nanorod arrays on transparent conductive substrates from aqueous solutions. Solar Energy. 2011; 85:2122-2129. http://dx.doi.org/10.1016/j. solener.2011.05.020

15. Cardenas M, Mendoza-Alvarez JG, Sanchez-Sinencio F, Zelaya-Angel $\mathrm{O}$ and Menezes C. Photoluminescent properties of films of CdTe on glass grown by a hot-wall-close space vapor transport method. Journal of Applied Physics. 1984; 56, 2977 2981. http://dx.doi.org/10.1063/1.333767

16. Portillo-Moreno O, Lima-Lima H, Lozada-Morales R, Palomino-Merino R, Zelaya-Angel O. $\mathrm{Cd}\left(\mathrm{S}_{(1-x)}+\mathrm{CO}_{3(\mathrm{x})}\right)$ thin films by chemical synthesis. Journal of Materials Science. 2005; 40:4489-4492. http://dx.doi.org/10.1007/ s10853-005-3939-7

17. Dávila-Pintle JA, Lozada-Morales R, Palomino-Merino MR, Rivera-Márquez JA, Portillo- Moreno O and Zelaya-Angel O. Electrical properties of Er-doped CdS thin films. Journal of Applied Physics. 2007; 101:013712-5. http://dx.doi. org/10.1063/1.2408380
18. Becerril M, Vigil-Galan O, Contreras-Puente G and ZelayaAngel O. Aluminum doping of CdTe polycrystalline films starting from the heterostructure CdTe/Al. Revista Mexicana de Física. 2011; 57:304-308.

19. Zhang Z, Tang Z, Kotov NA and Glotzer SC. Simulations and Analysis of Self-Assembly of CdTe Nanoparticles into Wires and Sheets. Nano Letters. 2007;7:1670-1675. PMid:17497820. http://dx.doi.org/10.1021/n10706300

20. Lalatonne Y, Richardi J and Pileni MP. Van der Waals versus dipolar forces controlling mesoscopic organizations of magnetic nanocrystals. Nature Materials. 2004; 3:121-125. PMid:14730356. http://dx.doi.org/10.1038/nmat1054

21. Baranov D, Fiore A, Van Huis M, Giannini C, Falqui A, Lafont $U$ et al. Assembly of Colloidal Semiconductor Nanorods in Solution by Depletion Attraction. Nano Letters. 2010; 10:743-749. PMid:20104878. http://dx.doi. org/10.1021/n1903946n

22. Hallock AJ, Redmond PL and Brus LE. Optical forces between metallic particles. PNAs. 2005; 102:1280-1284. http://dx.doi. org/10.1073/pnas.0408604101

23. Ortuño-López MB, Sotelo-Lerma M, Mendoza-Galván A, Ramírez-Bon R. Chemically deposited CdS films in an ammonia-free cadmium-sodium citrate system. Thin Solid Films. 2004; 457:278-284. http://dx.doi.org/10.1016/j. tsf.2003.11.169

24. Sandoval-Paz MG, Sotelo-Lerma M, Mendoza-Galván A and Ramírez-Bon R. Optical properties and layer microstructure of CdS films obtained from an ammonia-free chemical bath deposition process. Thin Solid Films 2007; 515:3356-3362. http://dx.doi.org/10.1016/j.tsf.2006.09.024

25. Mazón-Montijo DA, Sotelo-Lerma M, Quevedo-López M, El-Bouanani M, Alshareef HN, Espinoza-Beltrán FJ et al. Morphological and chemical study of the initial growth of CdS thin films deposited using an ammonia-free chemical process. Applied Surface Science. 2007; 254:499-505. http://dx.doi. org/10.1016/j.apsusc.2007.06.041

26. Pankove JI. Optical Processes in Semiconductors. New York: Dover Publications Inc.; 1971.

27. Löher T, Tomm Y, Pettenkofer C, Klein A and Jaegermann W. Structural dipoles at interfaces between polar II-VI semiconductors CdS and CdTe and non-polar layered transition metal dichalcogenide semiconductors $\mathrm{MoTe}_{2}$ and $\mathrm{WSe}_{2}$. Semiconductor Science and Technology. 2000; 15:514-519. http://dx.doi.org/10.1088/0268-1242/15/6/305

28. Shim M and Guyot-Sionnest P. Permanent dipole moment and charges in colloidal semiconductor quantum dots. Journal of Chemical Physics. 1999; 111:6955-6964. http://dx.doi. org/10.1063/1.479988

29. Nann T and Schneider J. Origin of permanent electric dipole moments in wurtzite nanocrystals. Chemical Physics Letters. 2004; 384:150-152. http://dx.doi.org/10.1016/j. cplett.2003.12.017

30. Tsai MH, Jhang ZF, Jiang JY, Tang YH and Tu LW. Electrostatic and structural properties of $\mathrm{GaN}$ nanorods/nanowires from first principles. Applied Physics Letters. 2006; 89:203101-3. http:// dx.doi.org/10.1063/1.2388129

31. Martin TP. Alkali halide clusters and microcrystals. Physics Report. 1983; 95:167-199. http://dx.doi.org/10.1016/03701573(83)90024-8

32. Yaroshenko VV, Annaratone BM, Antonova T, Thomas HM and Morfill GE. Dynamics of cluster particles in a dense plasma. New Journal Physics. 2006; 8:203-12. http://dx.doi. org/10.1088/1367-2630/8/9/203 
33. Allen PB. Dipole interactions and electrical polarity in nanosystems: The Clausius-Mossotti and related models. Journal of Chemical Physics. 2004; 120:2951-2962. http:// dx.doi.org/10.1016/S0927-0256(01)00159-8

34. Carlsson JM. Electronic structure of the polar $\mathrm{ZnO}\left\{\begin{array}{llll}0 & 0 & 0 & 1\end{array}\right\}$-surfaces. Computational Materials Science. 2001; 22:24-31. http://dx.doi.org/10.1016/S09270256(01)00159-8

35. Parker TM, Condon NG, Lindsay R, Leibsle FM and Thornton G. Imaging the polar (0001) and non-polar (1010) surfaces of ZnO with STM. Surface Science. 1998; 415: L1046-L1050. http://dx.doi.org/10.1016/S0039-6028(98)00563-9
36. Liu HM, Ma CY, Zhu C and Liu JM. Strain induced ferroelectricity in GdN: first- principles calculations. Journal of Physics: Condensed Matter. 2011; 23:245901-5. http://dx.doi. org/10.1088/0953-8984/23/24/245901

37. Kim YS, Kim J, Moon SJ, Choi WS, Chang YJ, Yoon JG et al. Localized electronic states induced by defects and possible origin of ferroelectricity in strontium titanate thin films. Applied Physics Letters. 2009; 94:202906. http://dx.doi. org/10.1063/1.3139767

38. Penn RL and Banfield JF. Self-assembly of (quasi) 0D nanoparticles. Geochimica et Cosmochimica Acta. 1999; 63:15491554. http://dx.doi.org/10.1016/S0016-7037(99)00037-X 